\title{
Issues and Technologies in Level Boarding Strategies for BRT
}

\author{
David Kantor, Gregg Moscoe, and Cliff Henke \\ WestStart-CALSTART
}

\begin{abstract}
A variety of advanced docking technologies are now becoming available. However, some cities are still choosing low-tech alternatives over effective and more expensive new technologies that are well-proven elsewhere in the world. As a preview of an upcoming WestStart-CALSTART white paper, this report roughly surveys various technologies and strategies to achieve level boarding, as well as the legal and operational rationales for employing them, the policies supporting or impeding these strategies, the technology choices various cities have made, and why some cities have decided to forgo an advanced technology solution in favor of one focused on management strategies. Where available, operational experience will be provided, as well as a comparison of implementation costs. Examples are drawn from both domestic and international applications. The upcoming WestStart-CALSTART white paper will discuss all of these concepts in the appropriate depth.
\end{abstract}

\section{Introduction}

Perhaps the most important component to facilitating ridership is level boarding, which is a system that places boarding platforms on the same level as the floor of the bus. Level boarding eliminates the need to ascend steps onto the bus, which can be difficult for the elderly or persons with mobility impairments, thus decreasing dwell times for all passengers. Buses can then be automated to dock precisely at bus stops-"precision docking"- thus providing easy access and enhancing 
passenger safety. It also eliminates the need for wheelchair lifts or similar costly devices. The technologies included in level boarding and precision docking for BRT include intelligent transportation systems (ITS), satellite-based technologies, onboard bridgeplates, and even simple driver training techniques, among others.

Cities that are examining BRT as an option have looked at level boarding strategies to help them achieve faster boarding and travel times. The FTA-CALSTART FY03 Market Demand Study found that 36 percent of BRT communities in the U.S. would like to consider the use of an automatic docking system to achieve level boarding. However, while a variety of docking technologies are currently becoming available, some cities are still choosing low-tech alternatives over effective and more expensive technologies that are well-proven elsewhere in the world. For example, in the U.S., one current system and two as yet unopened systems recently have opted for manual approaches with some assistance by doorway bridgeplates that deploy when the vehicle doors are opened, in lieu of mechanical, optical, or magnetic technology.

\section{Background: Rapid Growth of Interest in Low-Floor Buses and BRT}

Low-floor buses enable faster boarding and alighting of passengers than high-floor buses. Boarding times for ambulatory passengers on a low-floor bus are reported to be from 0.2 to 0.7 of a second faster per passenger, while alighting times are reported to be from 0.3 to 2.7 seconds faster. The shorter dwell times are just one of the myriad benefits for low-floor buses, and, as more and more agencies are demanding BRT and low-floor buses, the need to address level boarding as the next challenge has increased.

Internationally, BRT is on the rise on virtually every continent. Examples of new BRT projects include guided busways in several U.K. cities; a BRT plan for Jerusalem; a BRT strategy to replace an abandoned metro expansion in Bangkok; BRT expansion in Colombia, which builds on the success of the mode in its capital of Bogotá; and massive BRT plans in China, which will have six lines covering $300 \mathrm{~km}$ (188 mi), scheduled to open in time for the 2008 Summer Olympics.

Domestically, more than 50 communities are now developing BRT systems, according to the United States Senate Banking Committee. Since that 2003 estimate, the number is believed to have grown by four to six cities per year, as data compiled by CALSTART for FTA has pointed out. The outlook for this new mode 
of public transportation - arguably the fastest growing mode since the early days of light rail development-is unquestionably bright.

Additionally, some of the funding blockages that have been holding back recent BRT deployments appear to be dissolving. A large part of this is due to the recently-enacted reauthorization of federal transit and highway legislation: the Safe, Affordable, Fair and Efficient Transportation Efficiency Act-A Legacy for Users ("SAFETEA-LU"). SAFETEA-LU earmarked a variety of new projects for future funding, some of them with guaranteed amounts, while also creating a streamlined review of projects that seek less than $\$ 75$ million in federal New Starts funding (so called "small starts"), including BRT projects. In the wake of this policy change, many observers expect more cities to re-examine the case for BRT. Table 1 shows the awarded cities listed in the bill.

\section{Table 1. Cities Receiving "Small Starts" Funding in SAFETEA-LU}

\begin{tabular}{|lll|}
\hline Gainesville, FL & West Covina, CA & Chula Vista, CA \\
Fairfax Co., VA & Las Vegas, NV (2) & Jacksonville, FL (2) \\
New York, NY & Baton Rouge, LA & Seattle (I-405) \\
Sonoma County, CA & Chicago, Il (Cermack) & Lakeville, MN \\
Sevier County, TN & Denver, CO (US-36) & Rockville, MD (2) \\
Monrovia, CA (Villages) & Tampa, FL & Miami, FL (2-3) \\
Broward County, FL & Houston, TX & Minneapolis, MN \\
Albany, NY & Pinellas County, FL & Sevierville, TN \\
AC Transit (New lines) & Syracuse, NY (University Corridor) & Toledo, OH (2) \\
Los Angeles, CA (Crenshaw) & Atlanta, GA (Memorial Dr.) & Provo-Orem, UT \\
Eugene, OR (Phase 2) & Harrison County, MS & Glendale, CA \\
San Fernando, CA (Reseda) & Mississippi Delta, MS (I-69) & Rock Island, IL \\
Woodland Hills, CA (Pierce) & Boston, MA (Urban Ring) & San Antonio, TX \\
Orange County, CA & Charlotte, NC (sev. corridors) & \\
\hline
\end{tabular}

* Financial guarantees specified in the bill are in bold.

On the technological front, strong interest has been shown in automatic guidance and precision docking technologies for bus rapid transit applications, yet no city has implemented any of these technologies in the U.S. so far. However, Lane Transit District in Eugene, Oregon, and the Greater Cleveland Regional Transit 
Authority have been evaluating various technologies and appear ready to take a step toward implementation on their BRT projects, the EmX starter line BRT in Eugene and the Silver Line along Euclid Avenue, in Cleveland.

Both systems are studying deployment of the mechanical guidance technology used throughout the world, including those in Leeds and other guided bus corridors in Great Britain; in Adelaide, Australia; and in Essen, Germany. Cleveland and Eugene also will look at more sophisticated guidance systems for future phases of their BRT systems, possibly including electromagnetic, optical, satellite, or some combination of systems.

\section{Technologies to Achieve Level Boarding}

Guided vehicles, used in conjunction with stations having platforms at the same height as the vehicle floor, can be expected to have boarding and alighting times similar to those on heavy rail or on some LRT systems, or approximately one second per person less than the passenger service times for conventional buses. Besides reducing average passenger service times, this stepless and gapless boarding and alighting can significantly reduce the time it takes for customers with disabilities or customers with children in strollers to board and alight from BRT vehicles. This precision docking, combined with wide aisles, can significantly reduce passenger service times for these customers, thus improving schedule reliability.

There are two forms of precision docking to ensure level boarding: vehicle-based and driver-based. Vehicle-based precision docking systems include opticallyguided steering (as used in Rouen, France), electromagnetically-guided steering (such as Eindhoven's Phileas vehicles or the service vehicles in the Euro tunnel) or mechanically-guided systems (as used in several British cities in Adelaide, and in Essen). These automatic guidance systems can accurately steer the vehicle into alignment with the platform, achieving a high degree of precision and consistency.

Optical guidance uses a video camera positioned on the front of the bus to acquire position data and then transmits that data to a computer that then steers the bus. Optical guidance systems allow close passing and automated steering along narrow roads, which leads to high-speed entry into and exit from stations, which can result in both consistent, precise level boarding and significant time savings in station service/dwell times over manual steering. The French cities of Rouen and Clermont-Ferrand have been using optical guidance since 2001. Las Vegas was 
scheduled to utilize optical guidance beginning in fall 2003, but the system was turned off because the city's road maintenance staff could not keep the pavement stripe clean and well-defined in the city's extremely hot, dry, and sunny desert climate. Moreover, the transit agency's management found that the vehicles' drivers could manually steer the vehicle into the stations with sufficient precision.

Electromagnetic guidance systems involve either magnets embedded in the roadway or electrified subsurface cables. The positives are that the infrastructure technology (magnets) is less expensive than the mechanical approach but not as cheap as the optical approach (since it is striping only) and the onboard technology is slightly less expensive than the optical system (less than $\$ 100,000$ for optical systems per bus). Because there are only a few installations, the technology for transit applications is unproven.

FROG Navigation Systems, which provides magnetic guidance systems for the Dutch-based company APTS (producer of the Phileas BRT vehicle), has now established a facility in Charlotte, North Carolina. The FROG system utilizes an onboard inertial guidance system, which relies on magnetic markers for guidance correction. Although it has begun to sell its system for industrial warehouse applications in the U.S., FROG is also seeking demonstration or commercialization opportunities for BRT applications in North America.

Among various mechanical guidance systems is a version that utilizes an arm with a small rubber wheel on one end. The other end of the arm is attached to the bus steering axle such that, when it runs up against a concrete curb, it helps the driver guide the bus closer to the platform edge. Mechanical guidance systems have the advantages of tight running trajectories, precision docking, and a high degree of safety, simplicity, and robustness under severe operating conditions. The disadvantages include vehicle weight and the additional infrastructure necessary for them to work.

Yet another emerging approach is the use of advanced ITS technologies to provide lateral vehicle guidance. GPS-based technologies are used in about 75 percent of all automatic vehicle location (AVL) systems in the U.S., making them the most widely used location technology in the United States. GPS systems can locate the position of a vehicle to within two to five centimeters and can be operated anywhere the signals can be received. The costs per vehicle are moderate and can also be used in combination with ground-based radio-frequency monitoring for further accuracy (so-called differential GPS). These technologies can also support precision docking. 
However, not all precision-docking technologies are high tech. Sometimes, the platform can be detailed enough to provide a precision docking interface. The Kassel Curb, for instance, is a concrete curb with a concave profile on its street face. The driver steers the bus so the tires are forced against the curb, which, in turn, places the bus in the proper alignment with the platform edge. This system has been shown to meet the ADA Accessibility Guidelines ("ADAAG") gap standard in regular use, but it is highly reliant on the skill and diligence of the driver. It may also accelerate tire wear because of repeated contact with the curb, and the curb height must be coordinated to avoid conflicts with wheel nuts and vehicle door operations.

Without a precision-docking system, another possible option is the use of retractable bridgeplates to provide a barrier-free boarding interface. The vehicle is manually steered as close to the platform as possible, and the plate is then deployed to bridge the remaining gap. Like lifts, retractable ramps and bridge plates adversely impact dwell times and require regular maintenance. The disadvantages of this approach are the inability to service stations and stops without the appropriate platforms, as well as the extra maintenance costs entailed by the ramps. Since the devices extend from one or more bus doors, this obstacle could be overcome by having doors on both sides of the vehicles, or bridgeplates installed in only some of the doors, to be deployed as needed. Ramps would then be deployed as they currently are on traditional bus service, i.e., from a designated door only upon passenger need. However, this approach could reduce seating capacity, and the system would suffer from increased dwell times at the off-line stations. Lifts can be used instead of ramps when a system departs from the currently established U.S. trend.

There are exceptions to the rule that low-floor buses are required for level boarding. In fact, many systems outside the United States perform well without automatic guidance and precision docking technology. While most of the world's BRT stations use low platforms to match their low-floor vehicles, Quito's Trolebus, Bogotá's TransMilenio, and Curitiba's all-stop and direct express services actually provide high platforms. Some of these buses are especially equipped with a large ramp that deploys at stations to allow level boarding and alighting.

All of the aforementioned technologies can provide advantages well beyond precision docking: they also enable full guidance along an entire BRT route, which improves speed and also allows narrower lanes, saving on infrastructure costs. Currently, these technologies are being used in Europe in combination with such 
infrastructure strategies as fully grade-separated roadways and lanes (e.g., Leeds and Rouen), as well as queue-jumping lanes around mixed traffic only (also in several British cities).

\section{Management Techniques for Level Boarding}

Expensive guidance technologies have not been the only strategies employed to achieve precision docking and level boarding in BRT applications. For example, as was alluded to earlier, Las Vegas purchased its Civis vehicles from Irisbus with its optical system developed by Siemens/Matra in France. However, because of the difficulties in keeping the pavement striping crisp and clean-a significant issue for any optically-based tracking system as it is dependent on the clarity of the image-the system has been turned off and its use suspended while Siemens Matra continues to refine the pattern recognition software in the tracking system.

In the meantime, the Regional Transportation Commission, which was responsible for the BRT project in Las Vegas, learned that its drivers for the Civis fleet could steer the vehicle well enough to achieve a consistent and sufficiently close gap between vehicle floor and platform without the use of the guidance technology. Thus, the combination of driver training, the center drive position of the Civis vehicle, and pavement striping (even faded, it could be seen by the human eye well enough) has enabled manual precision docking.

This experience is somewhat corroborated by operations in Brisbane, Ottawa, and Bogotá, which have no precision docking technologies. In the South American examples, drivers use a combination of training, experience and marks on their buses' side mirrors (that they line up with the platform edge) to achieve a minimum gap between platform and vehicle. Some cities also penalize drivers for repeated bus body damage if they continue to brush the bus against the platform edge.

Further analysis of the various costs and benefits of level boarding strategies will be incorporated into the FTA-funded WestStart-CALSTART Level Boarding report. The report is expected to be released by the end of June 2006. 


\section{Policy Rationales for Level Boarding}

There are two fundamental policy rationales for offering transit patrons level access from stops or platforms to the vehicles (whether buses or railcars). First, level boarding enables a faster passenger flow both on and off the vehicles, which minimizes dwell times and decreases journey times. Shorter travel times enable a faster throughput, which has productivity advantages since fewer vehicles can serve the same or even improved schedules. This was one of the realized objectives of the Metro Rapid demonstration project in Los Angeles. Because bus speeds were improved up to 30 percent, the Los Angeles County Metropolitan Transportation Authority was able to offer service that was both faster and more frequent. At the same time, the authority has continued its local service in the same corridor without any additional buses and without additional operating costs.

The second rationale for level boarding is compliance with accessibility policies and regulations. Although level boarding can enable faster dwell and journey times, transit service must first meet the operational requirements to suit all passengers, including those with disabilities.

According to the Transportation Research Board,

... the platform/vehicle interface has a strong influence on passenger experience and boarding speed. Level boarding minimizes the horizontal and vertical gap between the platform edge and vehicle door threshold. This speeds boarding for all patrons and also allows wheelchair users to enter the vehicle without a lift or other assistance. For wheelchair access on fixed-guideway systems, the ADAAG allows a maximum vehicle floor-to-platform gap of 3 inches horizontally and 5/8 inch vertically. Although the ADAAG requirement for buses is not as stringent, this is the standard to meet for the highest-quality, barrier-free access. For a bus and platform to meet this standard, some form of precision docking system (or a vehicle- or platform-mounted retractable ramp or bridge plate) is required, the platform height must match the vehicle floor height, and the platform must be located along a tangent section of roadway. (Levinson et al., TCRP Report 90, Volume II: pg. 102)

When these words were written, "level boarding" and "fixed guideway" in this content were intended to mean rail systems. However, many believe that these standards can also apply to BRT, if the aforementioned gap dimensions can be ensured. Again, the white paper will delve deeper into these issues. 


\section{Legal Issues Regarding BRT Level Boarding}

The ADA requires low-floor buses to have ramps, while standard-floor buses must use wheelchair lifts. Both are required to install at least two sets of wheelchair securements per bus. In many other countries, accessibility policies do not require securements. For example, Britain's Disability Discrimination Act (DDA) currently requires what is referred to as the "protected position," which is a somewhat less secured arrangement to accommodate wheelchair passengers, leading to potentially less stable positions for these passengers. The "protected position" offers many benefits: a greater sense of independence for the passenger in the wheelchair; liberation from the hooks or belts often required to secure their position; a high level of safety; and faster boarding and alighting times. However, it does not meet the ADA requirements for a $20 \mathrm{~g}$ deceleration. Thus, for BRT applications in the United States, a waiver of the regulations would likely be required. Additionally, wheelchair passengers in this position are forced to face toward the rear, which can be an issue in the United States, since most seating layouts do not employ rear-facing seats and the philosophy of most accessibility advocacy groups stresses treatment of mobility-challenged people as part of the "mainstream" population as much as possible. However, just as with railcar seating layouts accommodating multiple door boarding, this may become less of an issue as more of the industry gains experience with BRT. If it becomes a norm of operation as in railcar layouts, they would not be made to "feel different" if they were facing backward as some others would also be facing that way.

This disparity in disabled passenger policy for buses around the world might be attributed to the respective countries' views on the purposes of public and private transit. In the United States, which has developed transportation policies that are heavily dependent upon the automobile, most public transit outside a few densely populated cities has been considered to be a niche system meant to serve transit-dependent populations: the elderly, the mobility impaired, and the poor. In the rest of the world, where public transportation is more generally accepted as an important part of transportation for all residents, its focus is to move as many people as efficiently as possible; the needs of the mobility challenged are often subsumed to those of the majority. However, both Canada and the U.K. are now looking at tie-downs, ramps, and more extensive demand response services for the persons with disabilities.

If ADA policy for buses applies to BRT (requiring securements and ramps), the end result will increase dwell times and decrease the productivity gains of the system, 
running in the face of the very purpose of BRT. If the federal government will adapt rail regulations to BRT, however, then the rail-required use of level boarding and precision-docking would preclude these inefficiencies, as precision-docking helps to ensure a minimal gap for level-boarding and alighting, acting as rails do for rail transit. The end result would be greater accessibility and boarding speed for the disabled without negating the other benefits accrued by the BRT system as a whole. In fact, the BRT system would be even more efficient for all passengers, due to its shorter dwell times. And since American public transit serves to a ridership with a disproportionate number of elderly and persons with disabilities in comparison to its population ratios, the system's benefits would seem tailor-made for current U.S. transit demographics.

\section{Rail Regulations and Adaptability to BRT}

At a recent $B R T$ conference for persons with disabilities, it was recommended that, while regulatory needs for BRT can be largely met by drawing from existing bus and/or rail regulations, the federal government should provide a greater amount of guidance on which elements of the bus regulations and which elements of the rail regulations apply to BRT systems. Additionally, it was suggested that when a BRT bus "acts" like a train, rail regulations should apply, and that when it "acts" like a bus, bus regulations should apply. The upcoming white paper will explore this question further and help provide recommendations. Of course, the BRT vehicles will be used outside the guideway in mixed traffic as with traditional bus service, so it is clear that that the mobility-challenged community favors policies in which BRT vehicles have both tie-downs and some interface technology to ensure level boarding.

\section{Case Studies}

\section{Leeds and Bradford}

Several subsidiaries of the British multinational bus and train operator First Group have implemented level boarding with mechanical guidance technology, the same as that pioneered in Essen and Adelaide. The cost per station is minimal: in Leeds, less than $\$ 10$ million total was spent by city authorities for precast concrete guidance curbs at 200 stations in the Superbus guided bus network. As part of a publicprivate partnership called a quality corridor agreement, First Group contributed roughly $\$ 20,000$ per bus to install a mechanical guidance arm on the steering axle 
of each low-floor bus operating in the network. It was part of new orders for both 12 meter (40-foot) single-deck and double-deck low-floor buses with Volvo and Wright Group. Level boarding is achieved by the driver manually steering the bus between the guidance curb at the station platform edge. The guidance arm keeps the bus close to the platform edge and as the driver brings the bus to a stop, he or she can turn the steering wheel to provide more tension on the arm, bringing the bus closer to the curb if necessary. The Superbus guided bus network has been so successful that, in Leeds, the investments by both the public sector and the private operator were paid for by the increased ridership in the third year of operation. Future plans call for expansions of the network and upgraded passenger amenities, such as real-time information displays.

\section{Curitiba and Bogotá}

Like most BRT systems outside the U.S., both of these cities have systems that use high-boarding platforms with ramps for accessibility and standard-floor buses without tie-down positions for wheelchairs. Drivers manually guide buses close enough to the platform edge of each station. As mentioned earlier, in Curitiba, drivers often mark notches in their side mirrors to help them guide the buses in place at each station by lining the mirror notch to the platform edge in their mirrors. Some operators in these cities financially penalize the drivers for damage to their buses, so they have a strong incentive to bring the bus close to the platform edge without actually hitting it.

In addition, operators in Curitiba also deploy bridgeplates from the bus doors to facilitate easier access across the gap between vehicle and platform. These devices in some cases deploy manually; in others, they deploy automatically as the bus doors open. At roughly 1,000,000 passengers per day, Bogotá's TransMilenio BRT network carries nearly as many people per weekday as the Washington, DC metro system. Curitiba's system, while not as heavily used, nonetheless carries a market share of more than 70 percent of trips in and out of the metropolitan area per weekday, despite Curitibans having the second highest automobile ownership rates in Brazil.

\section{Conclusion}

Level boarding and guidance technology are critical components of BRT, as they support the basic goals of BRT by reducing dwell times and, consequently, travel times. Achieving speedy and consistent service is essential to attracting new riders, 
and ease of boarding and exiting affect customer satisfaction and system performance.

Currently, there is no uniform level boarding strategy. Transit organizations address level boarding in different ways. While low-floor buses are the norm in the U.S., some of the original BRT systems in Bogotá and Curitiba utilize elevated platforms and high-floor buses with excellent results.

As advanced guidance technologies are entering service in a number of locales here and abroad, many transit systems are relying on less-sophisticated but effective mechanical and driver-based solutions. Again, those early BRT systems, as well as the transit properties in Las Vegas, rely on driver training and simple manual guidance assists to achieve reasonably consistent boarding results. Systems in Leeds and elsewhere have garnered excellent results with mechanical docking mechanisms.

As with many things, considerations of existing conditions, local needs, and budgetary issues, as well as local policy and labor agreements, will affect the choices individual systems make regarding level boarding and guidance technology. However, higher-level issues-such as the application of rail or bus accessibility standards to BRT - may have a greater impact in the long run.

\section{References}

Arrillaga, B., L. Wnuk, F. Silver. 2004. Bus rapid transit vehicle demand analysis update. USDOT \& FTA Office of Research, Demonstration, and Innovation; Office of mobility Innovation, Service Innovation Division. FTA-CA-26-70442003.2.

Diaz, B., M. Hardy, M. Baltes, L. Wnuk, and S. Zimmerman. 2004. Characteristics of bus rapid transit for decision-making. U.S. Federal Transit Administration, Report number FTA-VA-26-7222-2004.1. Washington D.C.

Levinson, H., S. Zimmerman, J. Clinger, J. Gast, S. Rutherford, and E. Bruhn. 2003. Transit Cooperative Research Program, Report 90, Volume II: Implementation guidelines. Washington D.C.

No author. 2005. Draft report: Bus rapid transit and accessibility for persons with disabilities consensus conference, key points summary. 
Transportation Management \& Design, Inc. 2002. Final report: Los Angeles Metro rapid demonstration program. Los Angeles County Metropolitan Transportation Authority and Los Angeles Department of Transportation. Los Angeles, CA.

U.S. Federal Transit Administration. 2005. Proceedings of the bus rapid transit vehicle working group meeting. Washington, D.C.

\section{About the Authors}

Cliff Henke, Gregg Moscoe and David Kantor are, respectively, Senior Director, Publications Editor, and Associate Project Manager at WestStart-CALSTART, a Pasadena-based nonprofit advanced transportation technologies R\&D organization. 